\title{
Research on the Development Countermeasures of Sports Tourism Industry from the View of Low Carbon Economy
}

\author{
Liu Bo ${ }^{1, a}$, Guo Hui ${ }^{2}$ b* $^{*}$ \\ ${ }^{1}$ Department of Shenyang University of Technology, Shenyang, Liaoning, China \\ ${ }^{2}$ Department of Shenyang University of Technology, Shenyang, Liaoning, China
}

\begin{abstract}
Low carbon economy is an important economic model that can promote its social transformation. Nowadays, low carbon economy has involved many industries. With the development of social economy, sports tourism industry is progressing continuously, and the proportion in social industry is getting higher and higher, which is of great practical significance to low-carbon economy. By analyzing the connotation of lowcarbon sports tourism and the relationship, its development strategy is discussed.
\end{abstract}

\section{Introduction}

With the continuous development of urbanization and the improvement of economic development level, the world climate and environment became worse and worse, having an adverse impact on social progress and development, so the low-carbon economy emerged and became the consensus of all countries. Low-carbon economy is a direction of sustainable development, and the sports tourism industry, as a constituent part of the modern economy, is also a sunrise industry developed under the perspective of low-carbon economy. Sports tourism is becoming a low-carbon and healthy lifestyle, will be accepted by more and more people, and then promote China's economic development.

\section{The Connotation of Sports Tourism Industry from the View of Low-Carbon Economy}

In order to better cope with global climate change and advocate the reduction of greenhouse gas emissions in production activities, the concept of low-carbon economic development has emerged. The so-called low-carbon mainly refers to the low emission of low greenhouse gases. In recent years, the low-carbon concept has gradually penetrated into the tourism industry, which belongs to the low pollution, low energy consumption, low emission green tourism industry, and has attracted wide attention in the world tourism industry. In the history of sports tourism development, low-carbon sports tourism is mainly through low energy consumption and low pollution tourists and elements, using low-carbon technology, implement the carbon sink mechanism, the construction of tourism facilities, tourism products, tourism environment and tourism consumption transformation, can make sports tourism can be more carbon development, so as to maximize the tourism economy, get better tourism experience, and on this basis to build an environmental and social benefits of the tourism model. For low-carbon sports tourism, the core of its development is to reform and improve the traditional sports tourism development mode through low-carbon policy, low-carbon technology and low-carbon management, so as to effectively reduce the greenhouse gas produced in the process of tourism development. The focus is to effectively protect the cultural and natural resources of the tourism sites by reducing the greenhouse gas emissions, which can not only effectively relieve the ecological pressure, but also better promote the development of sports tourism.

\section{The Necessity of Sports Tourism Industry Development under Low- carbon Economy}

At present, more people began to pay attention to the global abnormal climate change, how to solve the problem of global warming need people from all walks of life to pay great importance to, through the consultation between various countries, reached a consensus, is the high carbon model economic development into low carbon model, this way of development is the way of production, way of life and values. It has posed a challenge to the traditional tourism economy. If the transformation cannot be realized smoothly, it will seriously affect the sustainable development strategy. Therefore, the development of lowcarbon tourism is inevitable, and sports tourism, as a highly productive industry, is also an inevitable choice to conduct low-carbon economic development.

\footnotetext{
ae-mail:liubo@sut.edu.cn

* Corresponding Author:be-mail:guohui@sut.edu.cn
} 


\subsection{The Necessity of the Transformation of Traditional Sports Tourism}

Sports tourism industry itself has great development potential, and with the development of economy, consumption capacity is also constantly increasing, sports tourism is becoming more and more popular, tourism industry and sports industry are more closely integrated ${ }^{[1]}$ In recent years, many cities have paid more attention to the development of sports tourism industry and developed rapidly. However, now there are still a lot of local sports tourism industry are in the primary stage, the development of tourism products and resources is more traditional, so in the development of sports tourism resources, a lot of units also just pay attention to shortterm interests, do not pay attention to the continuous development, utilization and protection of resources, only pay attention to economic interests, do not pay attention to social humanities and ecological comprehensive benefits. In addition, due to the lack of market research, there are restrictions on product low-carbon development technology, and there is no standard evaluation system, so that the quality of many sports tourism products cannot meet the requirements of low-carbon economy.(pic.1)

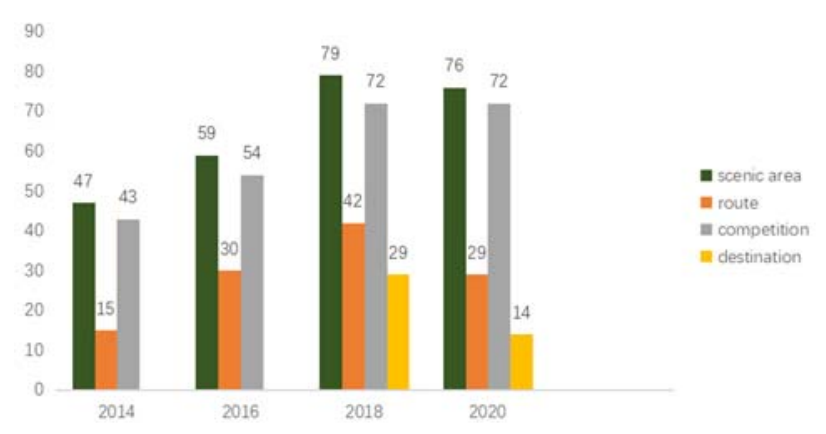

Figure 1. 2014-2020 Sports tourism quality items number statistics chart

\subsection{For Enhancing the Social Consensus on Low- Carbon Sports Tourism}

In order to better promote the development of the concept of low-carbon economy, we need the joint efforts of all fields of society. Only when the society as a whole conducts a low-carbon life can the ecological and lowcarbon development model be better realized. At present, the main obstacle encountered by the low carbon sports tourism industry is to change the tourism concept and way of tourists, because now many passengers still uphold the traditional concept, in the process of enjoying the concept, but in the process of tourism, low carbon tourism requires passengers to improve self-discipline, save environmental protection, green consumption, to better improve the utilization efficiency of sports tourism resources, better promote the harmonious development of sports tourism ${ }^{[2]} \mathrm{At}$ the same time, it is also necessary to improve the phenomenon of excessive environment damage and consumption of tourism resources, so as to better meet the development needs of low-carbon sports tourism. In the development stage of low-carbon sports tourism, many passengers may feel that it is a constraint to themselves, making their own tourism become under pressure. At the same time, although all walks of life are advocating green tourism, passengers 'environmental protection awareness is far from enough, the country' s publicity and education of low-carbon tourism is not enough, tourists have a clear understanding of this ecological and healthy consumption mode, and can not correctly understand the significance and value of low-carbon economy. Therefore, the whole society has the understanding of low carbon in the sports tourism industry. Sports tourism industry under the low carbon economy, or a new concept of development and values, but it is an important way to promote the development of tourism, this is also a very long-term process, the government, enterprises, passengers should act jointly, promote the development of low carbon sports tourism social cognition, make the concept of low carbon is more deeply rooted in the hearts of the people.

\subsection{Improves quality of Sports Tourism}

Previous economic development mainly depends on the expansion of fixed assets ${ }^{[3]}$, and continues until now. However, in the process of development, it often face two problems, one is the protection of the living environment and the other is the sustainable economic development. After so many years of efforts, to balance both, we must allow the economy to develop from the perspective of low carburization. Low carbon sports tourism industry is an important part of economic low carbon development, mainly depends on the concept of low carbon development and sustainable development, with the help of low carbon technology, to realize the scientific and reasonable application of sports tourism resources, at the same time with the help of low carbon concept to develop more sports tourism products, such as can carry out mountain climbing, bicycle, hiking and other low carbon ${ }^{[4]}$ Tourism mode, in the process of daily work as far as possible to choose low-carbon technology and materials, reduce the emissions of carbon dioxide and other greenhouse gases, so that not only to reduce the pollution caused by the atmosphere, but also to avoid the deterioration of the ecological environment, to ensure that sports tourism and social economy can achieve the maximum benefits. The concept of low-carbon sports tourism can transform relevant departments. Through the transformation of "carbon reduction", it can obtain greater economic benefits in the process of energy saving and carbon reduction and better promote the harmonious development of man and nature. In addition, the ecological environment needed in the development of sports tourism industry, and finally ensure its sustainable development. Therefore, we should pay attention to the comprehensive development of low-carbon sports tourism industry, introduce low-carbon concept in the process of sports tourism, choose low-carbon sports goods as far as possible, regularly maintain and update sports tourism products, and develop more low-carbon sports performance methods, fitness and leisure methods and sports training services.(pic.2) 


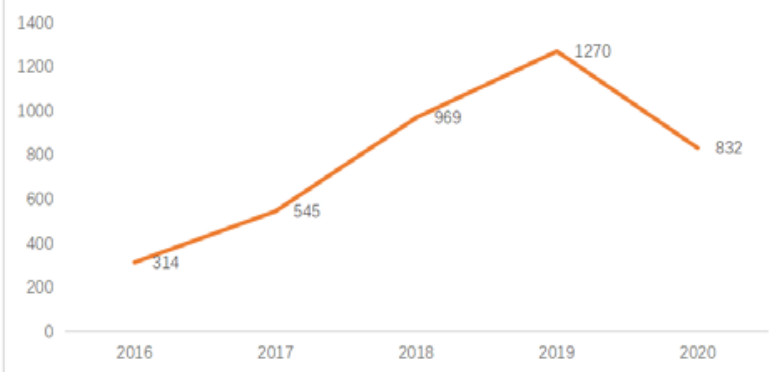

Figure 2. 2016-2020 The number or sports tourism quality projects declared nationwide

\section{Factors restricting the development of Low-carbon Sports Tourism}

\subsection{Awareness is relatively weak}

Sports tourism industry is a kind of sports and tourism combination industry, and has gradually become an important way of tourism, because the traditional sports tourism involves a large number of transportation, equipment, activity places, etc. and these will produce carbon dioxide. At the time when tourism began, it was called a smoke-less industry, but during its development, traditional tourism also created some ecological problems. A problem facing the development of low-carbon sports tourism industry now is that the low-carbon awareness of relevant personnel is still relatively weak, and because low-carbon sports tourism needs more environmental protection and low-carbon materials, which requires the increase of the cost of investment by developers, which is contrary to the original purpose. In the process of sports tourism development, too serious money awareness and too weak environmental awareness will have an impact on low-carbon tourism. Moreover, passengers 'awareness of environmental protection is relatively weak, and they care more about the experience in the process of sports tourism. At the same time, because passengers' low-carbon awareness is not enough, there will be a contradiction with the demand of sports tourism, which affects the development of sports tourism and is also an important restriction factor. In addition, some government departments ' awareness of environmental protection has gradually weakened, and they pursue too much political achievements, while ignoring the healthy and sustainable development of sports tourism, which restricts the development of low-carbon economy to a certain extent. Therefore, we must actively promote the low-carbon awareness.

\subsection{Lack of factor}

Many cities in China have very rich sports tourism resources, but because the traditional sports tourism only focuses on economic benefits, it ignores the ecological and environmental benefits ${ }^{[5]}$ Therefore, in the development and management of sports tourism industry without reasonable planning, do not pay attention to the environmental bearing capacity of planning, too blind in the process of development and management, even just to obtain more economic and massive changes in the local topography, make many areas of renewable resources and ecological environmental protection are seriously damaged, thus having a serious impact on the ecological environment, make the sports tourism industry deviate from the direction of low carbon environmental protection, does not conform to the low carbon economic concept. At the same time, sports tourism under the low-carbon economy is very low of management personnel, which also restricts the development of low-carbon sports tourism industry.

\subsection{Low Carbon Technology limitations}

The development of the low-carbon sports tourism industry involves many aspects, and the level of the application technology will also affect the development of the low-carbon industry of sports tourism. Sports Tourism Resources are the Foundation of the Low-carbon Sports Tourism Industry ${ }^{[6]} \mathrm{On}$ the basis of the tourism facilities, the tourists will provide more low-carbon sports tourism products, and then let the passengers feel the fun of leisure experience in the process of sports tourism.Sports tourism industry involves more content, such as the production of sports equipment, the design of sports tourism products, the building venues, etc. which need to be carried out on the basis of low carbon ${ }^{[7]}$ Therefore, the development of low-carbon technology will have some impact on the lowcarbon development of sports tourism industry. At the same time, the industry chain of sports tourism is very broad, and involves many industries, such as sports products raw industry, transportation industry, catering industry, etc. Only with a very perfect industrial chain, can we achieve the sports tourism industry. Nowadays, the industrial chain in many regions is not complete enough, and the applied low-carbon technology is not mature enough. It needs further innovation in technological progress and industrial upgrading, especially the manufacturing units of sports goods. The speed of product renewal and the pace of technology research and development are relatively slow. In addition, the layout and planning of the stadium is lack of scientific and reasonable, leading to the large construction energy consumption. Therefore, it is necessary to take measures to standardize the energy saving measures of the stadium from the source, show the energy conservation and environmental protection of the stadium, reduce the restrictive factors of the low-carbon development of sports tourism, and improve the efficiency of industrial development.

\section{Development Countermeasures of Sports Tourism Industry from the View of Low Carbon Economy}

\subsection{Adjusts the industrial structure}

First of all, optimizing the structure of low-carbon sports tourism industry is the core of realizing low-carbon 
transformation and development, and the essence of structural optimization development is to change the development mode. In the process of extending the sports tourism industry chain, we must have a reasonable division of labor for each industry. At the same time, the traditional development mode should be changed to make the sports tourism industry with low input and high output, strengthen the development of the sports tourism industry, and increase the low carbonization of the sports tourism industry ${ }^{[9]}$ Accelerate the speed of industrial transformation from low-end model to high-end model from labor-intensive to technology and labor-intensive development.

\subsection{Innovative production factor}

Compared with traditional industries, the development of low-carbon industries should strengthen the innovation of low-carbon technology and improve the production factors needed for the development of low-carbon tourism, this factors of production are still different from the past. Therefore, in order to make the low-carbon sports tourism industry get better and faster development, it is necessary to continuously optimize and innovate the production factors, so as to better improve the level of the production factors. That other words, we must invest more knowledge resources, human resources, technical resources and so on to ensure the development of low-carbon sports tourism has obvious advantages. So, the sports tourism industry needs to be ${ }^{[8]}$ The elements of production in the innovation, especially the relatively advanced and specialized elements. Advanced factors of production are obtained through long-term investment and cultivation, such as the corresponding research institutions, tourism resource centers, etc. In the development process of low-carbon sports tourism products, the professional development of products is the key, and technological innovation is the core of industrialization development. Therefore, we should introduce and cultivate more low-carbon sports tourism talents, innovate the mechanism of talent introduction and development, and improve the corresponding policies. The construction of the number of laboratories and entrepreneurial bases can be increased to provide a platform for training professional talents and reserve more talents. We should select more high-quality and applied-oriented young talents, cultivate more technical talents, and strengthen the construction of lowcarbon sports tourism.

\subsection{Overall Development Plan}

First, from the long-term analysis, we can find that clarify the status, development goals, development ideas, and corresponding safeguard measures, adjust industrial structure, optimize industrial layout, innovate low-carbon technology and improve infrastructure construction. Second, a reasonable industrial development plan should be formulated to promote the development of low carbonization. In the process of low carbon development of sports tourism industry, a detailed plan should be formulated to ensure its correctness, understand the actual carrying capacity of resources and environment, and develop within a reasonable range; third, improve the laws and regulations of low carbon sports tourism industry, improve low carbon concept, improve carbon emission payment system, strengthen supervision and ensure the implementation of policies.

\subsection{Changes traditional ideas}

First, we should actively publicize the awareness of lowcarbon sports tourism and environmental protection, enhance education, increase tourists 'awareness of lowcarbon economy, improve tourists' conservation and lowcarbon literacy, establish a low-carbon consumption concept, and make passengers realize their responsibility to protect the environment. It can also be publicized through the media, advocate the concept of energy conservation and environmental protection in the whole process of sports tourism, give up the traditional blind tourism mode, improve the low-carbon quality of passengers, and let passengers can take it as a duty and responsibility, so as to reduce pollution and reduce energy consumption. Second, the government needs to use more channels to make people understand and master the importance and significance of low-carbon sports tourism, and enhance people's understanding. The government can organize the relevant media to report more and let people know the benefits that can be obtained under this idea. In addition, the government should also formulate preferential treatment for the development of low-carbon sports tourism industry, encourage more enterprises to use low-carbon products, encourage passengers to use lowcarbon tourism methods, build a better atmosphere, and formulate a characteristic sports tourism system. Third, we should refer to the international mature system, and timely verify the greenhouse gas emissions in sports tourism, especially the carbon emissions, so as to ensure that they meet the standards and make the low-carbon sports tourism industry more standardized.

\section{Conclusion}

Low-carbon sports tourism industry is an important part of China's low-carbon economy development and the industrial advantage of low-carbon economy. Low-carbon sports tourism is the inevitable trend of the future sports tourism development, but it is also a long-term and arduous task, and we must make continuous efforts.

Develop and use the existing resources with the concept of low-carbon economic development. At the government level, we should guide the local economic development mode and increase the support for the development of low-carbon tourist attractions. For the development of local sports tourism resources, consider the bearing capacity of the local environment and the consumption of resources. Excessive consumption of energy and resources is also not suitable for the development of a low-carbon economy.

Formulate the low-carbon sports tourism development plans suitable for the local characteristics. Advanced factors of production are 
obtained through long-term investment and cultivation, and the natural environment can also be regarded as production factors, such as the development of skiing resources in Northeast China, which can take use of the unique natural conditions in the Northeast to carry out skiing projects. The corresponding research institutions, tourism resource centers can make use of their own advantages to develop low-carbon sports tourism projects suitable for local characteristics.

In short, low-carbon sports tourism is suitable for the direction of low-carbon economic development in China, and it is also an important field of low-carbon economy. As the sustainable development direction of the future, the sports tourism industry is an arduous project worth our efforts and thinking. Low-carbon sports tourism is in line with the development concept of the new era and the clear water and green mountains advocated by General Secretary Xi Jinping are golden and silver mountains. Under the new national development concept, low-carbon sports tourism must have a good development prospects.

\section{Acknowledgments}

Fund Project: Shenyang Social Science Project in Shenyang 《Countermeasures Research of Building Shenyang Sports City with the help of "One River" 》 (Project Number: SYSK2020-06-13); Undergraduate Education Teaching Reform of Shenyang University of Technology in 2020: 《Research on Badminton Teaching Reform in Shenyang under the Background of Education Innovation》

\section{References}

1. Liao Chun. Development Trend of Low Carbon Sports Tourism in China [J]. Athletics, 2011,18 (4): 53-56

2. Yi Fang. The Sustainable Development of Leisure Sports Tourism in the Low Carbon Economic Background [J]. Sports Space, 2016, (14): 114-114

3. White Manley, Yang Jiangling. Research of Low Carbon Sports Tourism in China [J]. Intellect, 2015, (33): 236,

4. Guo Hongtao. Industrialization of Sports Tourism Economy in Gansu Province [J]. Sports Space, 2016, (22): 122

5. Zou Yong. SWOT Analysis of Building Sports Tourism Economic Circle in Southwest China [J]. Journal of Sichuan Tourism Institute, 2017, (4): 56-58

6. SuXin. Analysis on the Disadvantages of Sports Tourism Economy in Liaoning Province [J]. China Business, 2012, (3): 188-189

7. Liu Ning. Research on Sports Tourism Industry Development from the View of Low Carbon Economy [D]. Master's thesis from Ocean University of China. 2014,(12):23
8. Liu Shanshan, Zhang Yu. Beautiful China Background Big Data Era Sports Tourism Internet Marketing Innovation [J]. China Management Information Technology, 2016 (3): 23

9. Deming. D evelopment Status and Pathath of Sports Tourism Industry in Yellow River Delta [D]. Master thesis, Qufu Normal University, 2011, (2) 30 